Friday, 22 July

Time: 1:30 PM

Session Number: 9.11: The Tourist Experience

Session Chair: Petr-Huerou, Christina, Tour University

Factors Effecting Destination Loyalty: A Case Cox's Bazar, Bangladesh

Hossain, M D Enayet, Curtin University

Quaddus, Mohammed, Curtin University

Shanka, Tekle, Curtin University

The Role of Eco-Cultural Attractions in Perception Engineering: A Study Conducted in Goa, India

Henthorne, Tony, University of Nevada, Las Vegas

George, Babu, University of Southern Mississippi 


\title{
FACTORS EFFECTING DESTINATION LOYALTY: A CASE OF COX’S BAZAR, BANGLADESH
}

\author{
Md. Enayet Hossain, Curtin University, Australia \\ Mohammed Quaddus, Curtin University, Australia \\ Tekle Shanka, Curtin University, Australia
}

\begin{abstract}
This empirical study was conducted to find out the determinants factors of loyalty for the destination Cox's Bazar, Bangladesh. We investigated the theoretical and empirical evidences for developing a comprehensive loyalty model in a tourism sector. Two formative and five reflective determinates were adopted from the literature and contextualised employing a qualitative research design. The interrelationships among adopted determinants were depicted based on literatures and field study. Forty three (43) measures were used in this study to collect data from 602 visitors. The model was tested employing Partial Least Square (PLS) based Structural Equation Modelling (SEM) approach. The result presented a strong support that "Perceived Satisfaction" is the main factor effecting "Destination Loyalty". The study also found that perceived quality and perceived sacrifice had direct positive effect on perceived satisfaction. The outcomes of this study contribute to determining the behavioural loyalty mechanism. The theoretical and managerial implications were presented based on the study findings.
\end{abstract}

\section{INTRODUCTION}

Loyalty behavior has generally been regarded as a desirable area of research (Alegre and Juaneda, 2006) because, among other things, it is thought that firstly, the marketing costs needed to attract loyal visitors are lower than those required for non loyal visitors. Secondly, a return (visitor) is a positive indicator of one's satisfaction. Thirdly, positive attitude of high repeaters increases their likelihood to return (Oppermann 1998). Study has documented that loyal consumers are more likely to act as free word-of mouth advertising agents that informally bring networks of friends, relatives and other potential consumers which account for up to 60\% of sales to new consumers (Chi and Qu 2008). With such exceptional returns, loyalty becomes an important strategic component for business firms. Recently, tourism researchers have incorporated the concept of loyalty into tourism consumers' choice behavior (Chi and Qu, 2008). However, it is observed that studies on tourism consumer choice have not been thoroughly investigated theoretically and empirically to explore for real mechanisms of tourism consumers' destination loyalty behavior. Indeed, understanding the determinant factors of destination loyalty will allow destination operators to concentrate on the major influencing factors that lead to visitors' to be loyal.

\section{BACKGROUND OF THE STUDY}

Nowadays, quality, satisfaction and destination loyalty have been measured as critical concepts for service industry. These are used as indicators of profitability and the successful achievement of organizational goals. Over emphasizing some factors like quality, satisfaction, and loyalty, while overlooking others, such as, risk, sacrifice, narrows down our view on certain factors that play important roles in consumers' choice decision (Kaili et al., 2007). So, the question could be has risen whether service quality is the only factor that directly influences consumers' satisfaction resulting in loyalty and, if so how is it formed?

In general, sustained destination loyalty depends on visitors' satisfaction, and satisfaction depends on how the consumers perceive different service qualities. These qualities vary with the variations in the nature of consumer perceptions of intrinsic and extrinsic quality cues associated with the products (Shahid 1997). Intrinsic cues are connected to the product's physical characteristics or core expectation from services. Extrinsic cues are external aspects (brand, warranty, price), but relate to a product's purchase decision (Kaili et al, 2007). However, the degree to which cues' associations influence quality is an open question. Little empirical evidence exists for service industry like tourism. Therefore, research is necessary to determine the roles of both cues in the same research setting.

In addition, measurement practices in business research are conventionally based on reflective constructs (Diamantopoulos, 2008). In recent years, researchers have recognised that construct become more sensible to reverse the causality, implying that a construct is a combination of its measures (Zabkar et al., 2010). This kind of situation a formative measurement model is necessary. The formative measurement construct represents the meaning of the indicators jointly in the relevant dimensions of the latent variable (Henseler et al, 2009). Therefore, this study was conducted to identify the main determinants of destination loyalty in the context of Cox's Bazar, Bangladesh, and to determine the influence of both intrinsic and extrinsic cues on perceived quality and perceived risk as formative constructs. 


\section{A BRIEF LITERATURE REVIEW AND PROPOSED MODEL}

In the literature, perceived value or customer satisfaction is widely recognised as a means to improve behavioural intentions and actual behaviour (Johnson et al., 2006). Empirically, however, perceived value and perceived satisfaction are closely related constructs although, a few researches used these two constructs separately within the same research setting (Lee, et al., 2007). In the context of our research we used perceived value (behavioural intention) and perceived satisfaction alternatively.

We reviewed more than 25 empirical studies (Agarwal and Teas 2004; Boshoff 2002; Petrick 2004a; Chi and Qu 2008; Lee, et al., 2007) [not included all for page limitations]. It was found that various authors used more than 30 factors in different research settings as determinants and/or evaluative factors of behavioural intention (value/satisfaction) and actual behaviour (loyalty). In fact, a model for loyalty research should incorporate some additional contextual factors that may influence the process of consumer choice decision making (like risk, sacrifice etc.). As it is too difficult to build a parsimonious loyalty model using all factors, we thus developed a proposed model based on three established behavioural theories and field study in Cox’s Bazar, Bangladesh (figure 1)

\section{BEHAVIOURAL THEORIES FOLLOWED FOR PROPOSED MODEL}

We considered Information Processing Theory (IPT) and Theory of Planned Behaviour (TPB) as basis to develop proposed loyalty model. We selected seven constructs in total for this study on the basis concept of "chunking" of IPT (Miller, 1956). Perceived quality (PQ) perceived sacrifice (PSR) of the current study have been developed from the concept of attitudinal behaviour and subjective norm of TPB. Perceived risk (PR) construct has been considered as behavioural control as per TPB (Ajzen, 1991) for this study [Details are not included for page limitations] In current research, the visitors' perceived satisfaction (PS) refers to behavioural intention, as it is the result of attitudinal behaviour (PQ), subjective norm (PSR), and behavioural control (PR) of TRA and TPB. PIC and PEC (see figure 1 for definition) are considered as environmental belief of TPB.

\section{FIELD STUDY FOR CONTEXTUALIZATION OF THE MODEL}

Since we are interested in developing an appropriate destination loyalty model in the context of Cox's Bazar, Bangladesh, we conducted 25 interviews in the field during March 2009 for contextualization of the theoretically developed model (Quaddus and $\mathrm{Xu}, 2005)$. We conducted content analyses of the interview transcripts. Altogether, initially 19 factors and 114 variables were identified from different interviews. We have tried to label the factors and variables in line with the literature. Finally, we used 43 measures for 7 constructs in this study. However, the variables within each factor and their meanings are different from the literature and are more specific for Cox’s Bazar [Measures are not included for limited page].

\section{HYPOTHESES}

Hypotheses depicted in the proposed model (figure 1) were developed based on literatures and field study. Hypothesis1a: PIC-PQ (+) Baker and Crompton, 2000; Petrick 2004a; Hypothesis1b: PEC- PQ (+) Petrick 2004a; Hypothesis 2a: PIC-PR(-) Agarwal and Teas 2004; Hypothesis 2b: PEC-PR (-)Agrwal and teas, 2004; Hypothesis 2c: PQ-PR(-) Bearden and Shimp, 1982, Field study; Hypothesis 2d: (PSR-PR(+) field study with support Snoj et al., 2004; Hypothesis 3: (PQ-PSR (+) Field study with support of Agarwal and Teas, 2004; Hypothesis 4a: PQ-PS (+) Zabkar et al., 2010.; Kaili Yieh et al, 2007 Hypothesis 4b: PR-PS (-) Agrawal and Teas, 2004, Snoj et al. 2004; Hypothesis 4c: PSR-PS (+), (Snoj et al., 2004; Sweeney et al, 1999); Hypothesis 5a: PS-PDL (+) Kaili Yieh et al,; Chi and Qu, 2008; and Hypothesis 5b: PQ-PDL (+) Zabkar et al. 2010, Field Study.

\section{RESEARCH METHOD}

\section{Measurement Model}

This study used a combination of qualitative and quantitative methods which has become increasingly popular in recent years (Bryman, 2006). In total 602 completed samples were collected from Cox's Bazar, Bangladesh with a set of pre-tested structured questionnaires using 6 point Likert Scale. Partial least Square (PLS) was used to analyse the data as it is most appropriate as the model incorporated both formative and reflective indicators (Chin 1998). As per PLS based SEM in the measurement part item loadings less than 0.6 were discarded from reflective constructs whilst for 'formative' constructs only weights were considered. Multicollinearity among the seven proposed indicators for intrinsic and eight indicators for extrinsic 
cues were assessed. Variance Inflation Factors (VIF) were between 1.122 and 1.455 for PIC, and between 1.193 and 1.564 for PEC, which were far lesser than acceptable level of 10 (Hensler et al., 2009). (Tables were not presented for page limitation). After discarding one measure from perceived quality (PQ5), two measures from perceived risk (PR1 and PR2), and three from perceived sacrifice (PSR2, PSR3, PSR5), item reliability (loading) ranged from .70 to .83 for reflective constructs of PQ, PR, PSR, PS, and PDL. The weights for formative constructs' determinants ranged from -0.235 to 0.453 , internal consistency values for reflective constructs of this study exceeded 0.7 (Nunnally, 1978). The lowest internal consistency for perceived quality was 0.792 while PDL had the highest of 0.895 . We found acceptable convergent validity since the average variance expected (AVE) ranged from 0.529 to 0.630 for reflective constructs (Fornell and Larcker 1981) [Tables are not included for page limitations].

\section{Structural Model}

Table 1 presents the results of estimated path coefficients (significant paths indicated with an asterisk), and associated t-value of the paths. Tests of significance of all paths were performed using the bootstrap re-sampling procedure. Path coefficient, interpreted like standardised betas indicated the strength of relationships between constructs. Nine (9) out of 12 hypothesized paths in the proposed model were found to be statistically significant at different significant levels. Three hypotheses (2a, 4c, and $5 b)$ were not supported at the acceptable $(0.01,0.05)$ levels. There was a significant impact of PIC and PEC on PQ with path coefficients of 0.158 and 0.478 . Perceived quality had impact on PS, PSR, PR, and PDL with path coefficients of 0.290, 0.390, -0.241, and -0.071 respectively (Table 1). Perceived Quality (PQ) which was direct and immediate antecedent of PSR, PS and PR was accounted for $29.8 \%$ of the variance. Perceived risk which was influenced by intrinsic and extrinsic cues as well as perceived quality and sacrifice accounted for only $15 \%$ with the path coefficient of $0.144,-0.244,-0.241$ and 0.149 respectively. No acceptable positive impact was found between PQ and PDL but established via satisfaction. For the antecedent of PS, both PQ and PSR were significant with path coefficient of 0.290 and 0.277 respectively. Although, the relationship between PR and PS was not statistically significant as per formulated hypothesis, result showed the right direction. These three antecedents were accounted for $22.9 \%$ of variance explanation. Surprisingly no satisfactory negative relation was found between PR and PS but path coefficient had right direction as per generated hypotheses. Finally, PS was found to be a direct antecedent of PDL with path coefficient of 0.624 explaining $35.9 \%$ of the variance. It is interesting to note that there was no negative relationship between PIC and PR directly but existed via PQ.

\section{THEORETICAL AND PRACTICAL IMPLICATION}

Our findings confirmed the argument that strong visitors 'satisfaction leads to destination loyalty. It is important to note that direct relationship between perceived quality and perceived destination loyalty was not supported, but indirect relationship exists between the two via perceived satisfaction. This might be true for the third world country like Bangladesh as visitors were much more conscious about satisfaction via quality. The relationship between perceived sacrifice and perceived satisfaction was established in this study which was not proven in prior literatures. This study proved the effect of intrinsic and extrinsic cues on quality individually. The relationship between Perceived intrinsic cue and perceived risk (H2a) was not supported because visitors thought the concerned destination as almost riskless. The relationship between perceived quality and perceived destination loyalty (H5b) was not supported as visitors were more conscious about satisfaction. They were more relaxed to be satisfied first and loyalty than quality to loyalty in the context of Bangladesh. Hypothesis H4c was not supported statistically, however, still under consideration to look for the cause behind in future research.

We found that visitors' satisfaction as main antecedent of destination loyalty that should be managed for enhancing destination loyalty. Perceived quality and perceived sacrifice were important factors in determining the perceived satisfaction. This suggests that once visitors become satisfied they have a greater tendency to continue to revisit the same destination. Therefore, policy makers should encourage service providers to keep improving on existing service as per expectation level of visitors by adding new services like good warranty facilities of the destination. Once the visitors become satisfied with their staying they would tend to stay longer and their behaviour would become conducive leading to sustainable loyalty.

\section{LIMITATION AND FUTURE RESEARCH DIRECTION}

There are some limitations of the study. Firstly, we used the data collected only from Cox's Bazar, Bangladesh particularly beach based which may not be applicable to general destinations settings. Secondly, perceived intrinsic and extrinsic cues used as formative constructs in the study may not permit generalisation of the relevant indicators across different destinations. Thirdly, we discarded some variables on the basis of loading which might be not always rational. Finally, we did not consider the impact of moderating variables like gender, age and education generated from field study. We believe that this may affect destination choice decisions factors differently. 
Result of tests of hypotheses

TABLE 1

\begin{tabular}{|c|l|c|c|l|l|l|l|}
\hline HY & \multicolumn{1}{|c|}{ PR } & PC & $\mathrm{t}-\mathrm{V}$ & CO & \multicolumn{1}{c|}{ CR } & AVE & \multicolumn{1}{c|}{$\mathrm{R}^{2}$} \\
\hline H1a & PIC-PQ (+) & 0.158 & $3.784^{* *}$ & PIC & - & - & - \\
\hline H1b & PEC-PQ (+) & 0.478 & $10.63^{* *}$ & PEC & - & - & - \\
\hline H2a & PIC-PR (-) & 0.144 & 2.786 & PQ & 0.857 & 0.546 & 0.298 \\
\hline H2b & PEC-PR (-) & -0.244 & $2.67^{* *}$ & PR & 0.839 & 0.566 & 0.150 \\
\hline H2c & PQ-PR (-) & -0.241 & $4.112^{* *}$ & PSR & 0.792 & 0.560 & 0.152 \\
\hline H2d & PSR-PR (+) & 0.149 & $3.875^{* *}$ & PS & 0.849 & 0.529 & 0.229 \\
\hline H3 & PQ-PSR (+) & 0.390 & $12.042^{* *}$ & PDL & 0.895 & 0.630 & 0.359 \\
\hline H4a & PQ-PS (+) & 0.290 & $7.292^{* *}$ & & & & \\
\hline H4b & PSR-PS (+) & 0.277 & $7.145^{* *}$ & & & & \\
\hline H4c & PR-PS (+) & -0.033 & 0.754 & & & & \\
\hline H5a & PS -PDL (+) & 0.624 & $16.136^{* *}$ & & & & \\
\hline H5b & PQ-PDL(+) & -0.071 & 1.954 & & & & \\
\hline
\end{tabular}

(HY=Hypotheses,

$\mathrm{PR}=$ Path Relation, $\mathrm{PC}=$ Path

Coefficient, $\mathrm{t}-\mathrm{V}=\mathrm{t}$

Statistics,

$\mathrm{CO}=$ Constructs,

$\mathrm{CR}=$ Composite

Reliability, AVE=

Average Variance

Extracted,

**Significant at $\mathrm{P}<$

$.01)$

Tourism Destination Loyalty Model

FIGURE 1

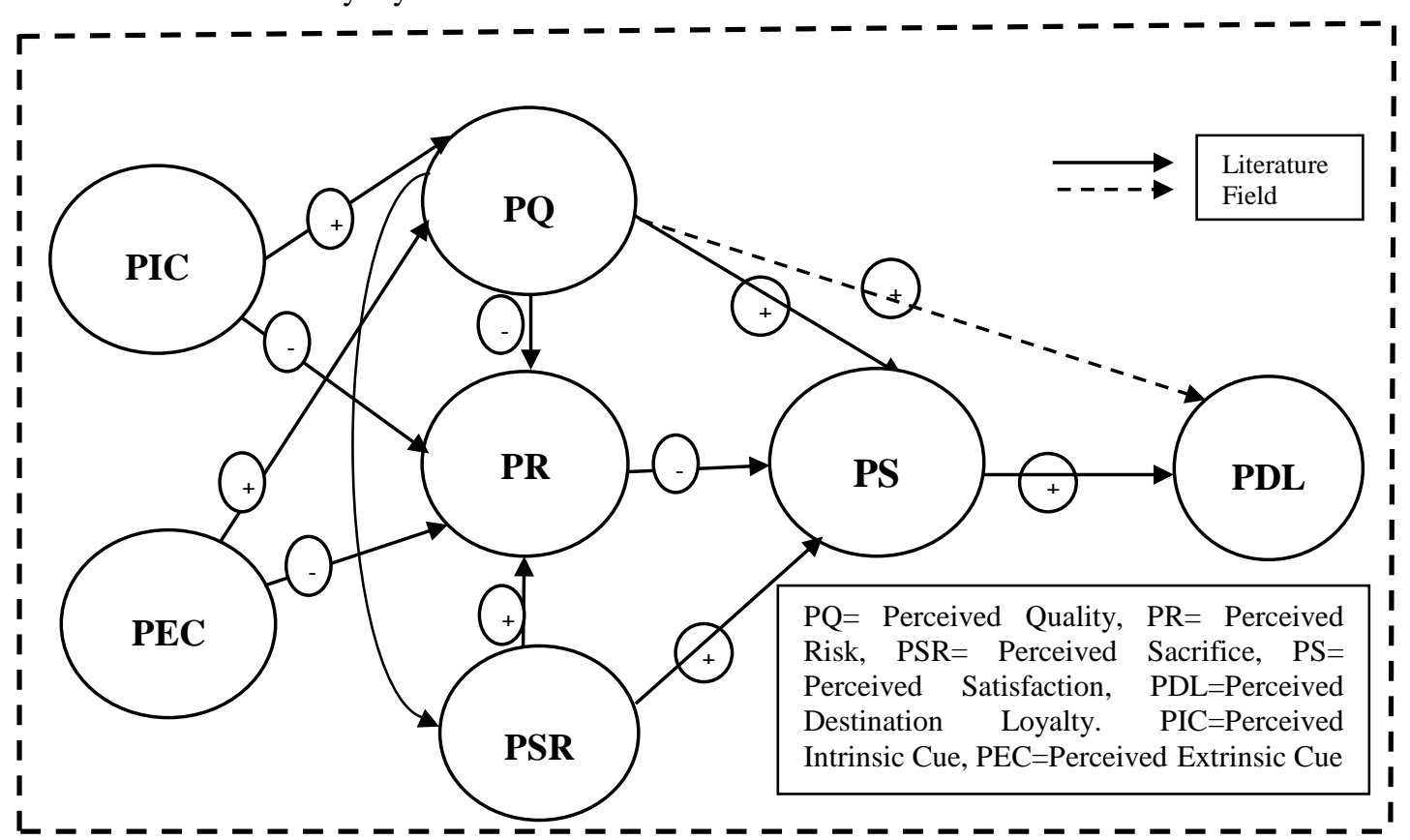

REFERENCES

Agarwal, S. and Teas, R. K. 2004. “Cross-national Applicability of a Perceived Risk Value Model.” Journal of Product and Brand Management, 28(2), 242-256.

Ajzen, I.,1991. “The Theory of Planned Behaviour.” Organizational Behaviour and Human Decision Processes, (50), 179-211.

Alegre, J. and Juaneda, C. 2006. “Destination Loyalty, Consumers’ Economic Behaviour.” Annals of Tourism Research, Vol. 33(3), pp. 684-706.

Baker, D. A., \& Crompton, J. L. 2000. “Quality, Satisfaction and Behavioural Intentions.” Annals of Tourism Research, Vol. 27(3), 785-804. 
Bearden, W.O. and Shimp, T .A., 1982. "The Use of Extrinsic Cues to Facilitate Product Adoption.” Journal of Marketing Research, 19, 229-239.

Boshoff, C. 2002. “Service Advertising: An Exploratory Study of Risk Perceptions.” Journal of Service Research, 4 (4), 290-298.

Bryman, A. 2006. “Integrating Quantitative and Qualitative Research: How is it done?”. Qualitative Research, Vol. 6(1), pp. 97-113.

Chi, G. O.C. and Qu. H. 2008. "Examining the Structural Relationships of Destination Image, Tourist Satisfaction and Destination Loyalty: An Integrated Approach.” Tourism Management, (29), 624-636.

Chin, Wynne W. 1998. The Partial Least Square Approach to Structural Equation Modeling in Modern Methods for Business Research. G. A. Marcoulides, ed. Mahwah, NJ: Lawrence Erlbaum, 295-336.

Diamantopoulos, A. 2008. "Formative indicators: Introduction to the special issue.” Journal of Business Research, 61(11), 1201-1202.

Fornell and David F. Larcker 1981. "Evaluating Structural Equations Models with Unobservable Variables and Measurement Error.” Journal of Marketing Research, (18), 39-50.

Henseler, J., Christain, M., Ringle,R,. \& Sinkovics 2009. "The use of Pertial Least Square Path modelling in international Marketing”. Advances in International Marketing, (20), 277-319

Johnson M.D., Herrman A., and Huber F, 2006. “The Evaluation of Loyalty Intention.” Journal of Marketing, 70, 122- 132

Kaili Y., ,Yu-Ching C., \& Ya-Kang C., 2007. "Understanding the Antecedents to Customer Loyalty by Applying Structural Equation Modelling.” Total Quality Management

Lee,S.Y.,Petrick,J.F.,\& Crompton,J.2007. "The roles of quality and intermediary Constructs in determining festival attendees’ behavioural intention.” Journal of Travel Research, Vol. 45(4), 402-412.

Miller, G.A. (1956). The Magical Number Seven, Plus or Minus Two: Some Limits on Our Capacity for Processing Information. Psychological Review, 63, 81-97.

Nunnally, J.C., (1978).Psychometric Theory. New York, NY: McGraw-Hill

Operman, M. 1998. "Destination Threshold Potential and the Law of Repeat Visitation. Journal of Travel Research." Vol. 37(2), pp. 131-137.

Petrick J. F. 2004a. “Are loyal Visitors’ Desired Visitors?” Tourism Management, (25), 463-470.

Quaddus M., Xu J., 2005. “Adoption and Diffusion of Knowledge Management System: Field Studies of Factors and Variables”. Knowledge Based Systems, (18), 107-115.

Shahid, B. N. 1997. "Marketing Cues and Perceived Quality: Perception of Saudi Consumers Towards Products of the U.S, Japan, Germany, Italy, U.K. and France”. Journal of Quality Management, 2(2), 217-234.

Snoj. B, Korda, A.P., Mumel,D., 2004. "The relationship among perceived Quality, Perceived Risk and Perceived product value.” Journal of product and Brand Management, 13(3), 156-167

Sweeney, J.C., Soutar, G.N. and Johnson, N.W. (1990). The role of Perceived Risk in the quality-value relationship; a study in the retail environment. Journal of Retailing, 75(1), 77-105.

Zabkar, V., Brencic M M., and Dmitrovic, T., 2010. "Modelling Perceived Quality, visitor satisfaction and behavioural intentions at the destination level”. Tourism Management, (31), 537-546. 